\title{
Atmosphäre des Pessimismus in Guimarães Rosas «A velha» («Die Greisin»)
}

\begin{abstract}
Desde o tríduo de noites, no caso meu, e até hoje, nunca mais veio-me a empolgo, fatalmente da fé, a dita experiência. Isto faz parte da tristeza atmosférica? Tento por vão meios, ainda que cópia, recaptá-la. Aquilo, como um texto alvo novamente, sem trechos, livrados de enredo, ao fim de ásperos rascunhos. Mas tenho de relê-los. O tempo não é um relógio - é uma escolopendra.
\end{abstract}

Guimarães Rosa ${ }^{1}$

\section{Das Schreiben als Umdeutung des Erlebten}

Die ästhetische Arbeit des brasilianischen Schriftstellers João Guimarães Rosa stellt eine textuelle Herausforderung dar, die ein genaues Untersuchen der sprachlichen Aspekte, seiner Komposition und seines biografischen Umfelds erfordert. Nicht selten sind diese drei Dimensionen in den Arbeiten der Schriftstellers eng miteinander verwachsen. Persönliche Erfahrungen spiegeln sich zweifellos in seinen ästhetischen Kreationen wider. Erinnerung, Erfahrung und Narrative sind untrennbar miteinander verbunden, da die vielfältigen Begegnungen und Erlebnisse, die den Autor beeinflusst haben, prägen seine Arbeit am Text. Erlebtes materialisiert sich durch den narrativen Akt, der die Erinnerungen umdeutet.

Texte, die von den genannten Schnittpunkten ausgehen, sind polysemisch, intertextuell und intratextuell. In seinem Schreiben verwandelt Rosa die gemachten Erfahrungen in ein ästhetisches Produkt, das über die reine Wiedergabe des Erfahrenen hinaus geht. Die Vielfalt der Erfahrungen macht den Text und damit auch das Interpretieren komplexer. In diesem Artikel geht es um das Feld zwischen Schreiben, Leben und Rezeption des Schriftstellers.

Arbeiten, die Schnittstellen zwischen der Biografie des Schriftstellers und der literarische Fiktion untersuchen, sind in der Literaturwissenschaft nicht neu

1 João Guimarães Rosa: Tutameia: terceiras estórias. Rio de Janeiro: Nova Fronteira 2017, S. 184. Freie Übersetzung: «Seit dem Triduum der Nächte, in meinem Fall, und bis heute ist mir diese Erfahrung, lebensbedrohlicher Glauben, nie wieder zuteil geworden. Ist das Teil der atmosphärischen Traurigkeit? Ich versuche es mit mehreren Mitteln, auch wenn nur als Abbild, sie wiederherzustellen. Dies ist erneut ein Text mit Ziel, ohne Abschnitte, losgelöst von Handlung, letzten Endes Rohentwürfe. Aber ich muss sie noch einmal lesen. Die Zeit ist keine Uhr - sie ist ein Scolopendra.»

Ә Open Access. (C) 2020 Andressa L. M. Medeiros, publiziert von De Gruyter. (c) BY-NC-ND Dieses Werk ist lizenziert unter der Creative Commons Attribution-NonCommercial-NoDerivatives 4.0 Lizenz. https://doi.org/10.1515/9783110677713-009 
und somit gibt es bereits mehrere Beispiele des methodischen Vorgehens. Im Rahmen dieses Beitrags wird untersucht, inwieweit sich historische Realität und autobiografische Aspekte im Text «A velha» («Die Greisin») ${ }^{2}$ wiederfinden lassen. ${ }^{3}$

Obwohl die biografischen Daten als möglicher Interpretationsschlüssel eine besondere Stellung einnehmen, stellen die Werke auch unabhängig von ihnen eine eigene sinnvolle Entität dar. Das heißt im Umkehrschluss, dass sich niemals alle Bedeutungszuschreibungen und Interpretationen des fiktionalen Werkes auf die Autobiografie zurückführen lassen. Objektive Verweise auf einen historischen und biografischen Kontext können ohne Schwierigkeit identifiziert werden, wohingegen Erlebtes und Erinnerungen technisch umgedeutet und transformiert in die Arbeit einfließen. Manchmal sind diese Bezüge eindeutig, sofern man ein minimales Wissen über den historischen und biographischen Kontext voraussetzen kann. Das bedeutet aber selbstverständlich nicht, dass keine anderen Lesarten möglich wären.

Dies mag angesichts der Debatte zwischen immanenten und biographischen Ansätzen widersprüchlich erscheinen. Daher soll das Thema im Folgenden genauer eingegrenzt werden. Auch wenn es stimmt, dass die autobiografischen Komponenten nicht die gesamte Bedeutung des Textes beinhalten, sind sie sowohl in der textuellen Dimension als auch in der Dimension der Rezeption relevant, da die gelebte Erfahrung die Textgestaltung ästhetisch beeinflusst.

Ottmar Ette ${ }^{4}$ geht in seinen Erwägungen zu Erich Auerbach und dem von ihm geprägten Begriff der Figuraldeutung auf die Beziehung zwischen der «autobiografischen Isotopie» und der «Isotopie der Gemeinschaft» ein. Laut Ette spiegelt die individuelle Erfahrung (Emotionen, Empfindungen, Erinnerungen) die kollektive Erfahrung auf textueller Ebene. Ette führt hierzu aus:

[...] Das autobiographische Funktional ist - gerade mit Blick auf die Rezeption - von größter Wichtigkeit. Es ist emotional wahrlich ergreifend und schreibtechnisch subtil, doch letztlich nicht die Bedeutungsebene, von der aus alle anderen Texetlemente von Mimesis - auch nicht als Figuraldeutung - Sinn erzeugen. Sie ist gleichwohl Bestandteil jener Sinnlichkeit,

2 Für die portugiesischen Auszüge aus «A velha» wurde die noch unveröffentlichte deutsche Übersetzung von Anna Scheifler, überarbeitet von Judith Jennert und Paulo Soethe herangezogen.

3 Vgl. Philippe Lejeune: O pacto autobiográfico: de Rousseau à Internet. Belo Horizonte: Editora UFMG 2008; Helmut Galle: Elementos para uma nova abordagem da escritura autobiográfica. In: Matraga 18 (2006).

4 Ottmar Ette: ÜberLebenswissen. Die Aufgabe der Philologie. Berlin: Kadmos Kulturverlag 2004. 
die der Text in seiner Gesamtheit ausstrahlt und der Leserschaft vermittelt. [...] Neben die autobiographische Isotopie tritt von Beginn an jene der Gemeinschaft; gemeinsam bündeln sich beide immer wieder um das individuelle Erlebnis kollektiver Geschichte, die sich auf der Inhalts- wie auf der Ausdrucksebene in ständig neuen Variationen zeigt. ${ }^{5}$

Der Textauszug verdeutlicht, dass der autobiografische Charakter einen wesentlichen Teil der Textdimension darstellt, da er entweder durch die Wahl des Inhalts, die verwendete Ästhetik oder die gewählte Ausdrucksform als Teil der Isotopie im Werk erscheint.

Die autobiografischen Isotopien und die Isotopien der Gemeinschaft liegen im Text in einer Reihe von Zeichen vor. Die Verknüpfungen im Text sind von Figuren und Symbolen durchsetzt, die eine referentielle Illusion der Weltbilder darstellen und die durch die Kommentare des Erzählers zur Umgebung, die als Orientierung beim Lesen dienen, sensorisch wahrgenommen werden.

In der analysierten Erzählung "A velha» («Die Greisin») ragt der Pessimismus als zu untersuchende Kategorie im Erzählstil heraus. Durch den Erzähler wird er über die sensorische Wahrnehmung der Umgebung vermittelt, während die kollektive Zeit der Narrative durch Zeichen hergestellt wird, die die historische Zeit anzeigen. Der Schriftsteller transformiert die gelebte in eine fiktive Wahrnehmung. Diese Wahrnehmung existiert möglicherweise bereits im Werk selbst, auf jeden Fall in der Dynamik seiner Rezeption, oder eventuell in beiden Ebenen. Das fiktionale Werk entsteht aus einem Bereich, der sich aus mehreren Elementen zusammensetzt: Schreiben und Leben; ästhetisches Schaffen und das Herstellen textueller Verbindungen; individueller Erfahrung, die die kollektive Erfahrung widerspiegelt und vom Lesenden durch illusorische Bezüge zur Welt und durch Kommentare des Erzählers zur Umgebung wahrgenommen wird.

Die Arbeit von Guimarães Rosa präsentiert verschiedene Variationen des Inhalts und des Ausdrucks autobiografischer und gemeinschaftlicher Isotopien. Es hat sich herausgestellt, dass «A velha» ${ }^{6}$ («Die Greisin»), eine der drei deutschen Erzählungen in Ave, Palavra ${ }^{7}$, viel Material bietet, um den autobiografischen Bezug in der verwendeten Ästhetik der Geschichte zu untersuchen. Denn sie strahlt Sinnlichkeit aus und erzeugt einen Präsenzeffekt, der in der kollektiven und individuellen Erfahrung, sowohl inhaltlich als auch der Form nach, wahrgenommen wird.

5 Ebda., S. 60.

6 Erstmals in der Zeitung $O$ Globo am 3. Juni 1961 veröffentlicht.

7 João Guimarães Rosa: «A velha». v. 2. In: Ficção completa: Ave, Palavra. Rio de Janeiro: Nova Fronteira 2017, S. 921-923. 
Wie bereits Paulo Soethe ${ }^{8}$ darlegte, spielen die deutschen Erzählungen auf den biografischen Kontext des brasilianischen Autors an. Ins Gewicht fällt insbesondere seine Zeit als Diplomat in Hamburg während des NS-Regimes, im Dienst des Estado Novo. ${ }^{9}$ Obwohl der autobiografische Kontext Rosas nicht die zentrale Dimension bei der Sinngebung der Erzählung darstellt, so kann er sowohl als interpretativer Schlüssel der Texte als auch zum Verstehen der ideologischen Position des Schriftstellers und Diplomaten, angesichts des sozialen, historischen und kulturellen Kontexts, in dem er sich in Deutschland und Brasilien befand, dienen. Die Ausführungen Soethes verdeutlichen den Einfluss der beiden von Ette festgelegten Isotopien. Um zu verstehen, inwieweit Erlebtes und Isotopien in das Schreiben und in die Bedeutungszuschreibung involviert sind, wird betrachtet, was an der Schwelle zwischen Schreiben und Leben geschieht.

Dahingehend kann die Erzählung als diskursiver Raum betrachtet werden, den das Erzählende Ich literarisch nutzt, um traumatische Erfahrungen des Erlebenden Ichs zu verarbeiten. Der Schreibprozess dient als eine Art unbewusste Geschichtsschreibung. ${ }^{10}$

\section{Narrative und Trauma}

Das in der Erzählung «A velha» («Die Greisin») behandelte Thema weist Ähnlichkeiten mit dem realen Handlungsraum Guimarães Rosas auf, woraus man schließen kann, dass der Schriftsteller eine Art selbstkritisches Alter Ego geschaffen hat, um die individuellen und kollektiven traumatischen Erinnerungen und Erlebnisse dieser Zeit zu verarbeiten. Jaime Ginzburg vermutet, dass Rosa in den Narrativen seiner deutschen Erzählungen einen diskursiven Raum gefunden ha-

\footnotetext{
8 Paulo Astor Soethe: Os humores de Wotan: fontes alemãs de Guimarães Rosa. In: Antonio Donizeti da Cruz/Lourdes Kaminski Alves (Hg.): Literatura e sociedade no contexto latino-americano. Cascavel: EdUnioeste 2012, S. 223-240.

9 Als «Estado Novo» («Neuer Staat») wird die Zeit der autoritären Diktatur in Brasilien von 1937 bis 1945 unter Getúlio Vargas bezeichnet.

10 Jaime Ginzburg äußert sich zu Adornos Konzept zu Kunstwerken, die in traumatischen Zeiten entstanden sind und stellt fest, dass diese als unbewusste Geschichtsschreibungen nicht immer explizit auf der Oberfläche des Textes wirken, sondern sich in der Erzählweise manifestieren, die durch latente Erinnerungen an Traumata und durch Metaphern, die die Atmosphäre und die erlebten Empfindungen wiedergeben, gekennzeichnet ist. Vgl. Jaime Ginzburg: Guimarães Rosa e o terror total. In: Cornelsen, Elcio; Burns, Tom (Hg.): Literatura e guerra. Belo Horizonte: Ed. UFMG 2010, S. 17-27.
} 
be, um die Problematik der Einschränkung seiner kreativen Fähigkeiten angesichts der Gewalt des Krieges auszudrücken. ${ }^{11}$

In «A velha» («Die Greisin») spiegelt sich dieser Prozess in der thematischen Auseinandersetzung mit dem NS-Regime und der Verfolgung der Juden wider. Die Hauptfiguren sind ein brasilianischer Konsul und eine alte Frau, die ihn bittet, ihrer jüdischen Tochter zu helfen. Die potenzielle Schuld des Konsuls, der der alten Dame nicht beisteht, lässt sich in der erzeugten Atmosphäre von Verzweiflung und Hoffnungslosigkeit spüren.

Ginzburgs Überlegungen hallen auch in Guimarães Rosas Interview mit Günter Lorenz wider, in dem Rosa offenlegt, dass die Ethik und das Engagement für die Menschheit seiner Meinung nach durch die Sprache etabliert wird. In Anbetracht dieser Aussage könnte ein solches ethisches Verfahren auch in «A velha» («Die Greisin») vertreten sein.

Durch Ginzburg wird eine Reflexion über das Thema Trauma und die narrative Erfahrung angeregt, die in der Arbeit «Erinnerungsräume» ${ }^{12}$, vor allem im Kapitel IV «Körper» von Aleida Assmann vertieft wird. Laut Assmann sind Erinnerungen Spiegelbilder der objektiven Realität, die durch die Wahrnehmung der Vergangenheit kontaminiert sind. Erinnerungen werden durch den Prozess der Verdichtung und Selektion gebildet und gemäß den Veränderungen in den Deutungsmustern umgedeutet. In "A velha» sind die autobiografischen und historischen Zusammenhänge überprüfbar, was nicht bedeutet, dass sie der objektiven Realität des Erlebenden Ichs entsprechen. Für Assmann ${ }^{13}$ führen die Erinnerungen an traumatische historische Ereignisse möglicherweise nicht zu einem kohärenten historischen Bild, da sie sich um Ansammlungen von Erinnerungen strukturieren, die in Empfindungen gehüllt sind, die vom affektiven Druck des erlebten historischen Ereignisses herrühren. Sie basieren also nicht immer auf tatsächlichen Ereignissen, sondern werden aus Gefühlen und Atmosphären während des Ereignisses gebildet. Trotzdem sind sie legitim und zuverlässig, da die Lebendigkeit jenes historischen Moments für das Erlebende Ich vom Erzählenden Ich wiedererlangt wird.

In Texten, die von traumatischen Erlebnissen inspiriert sind, werden oft Metaphern verwendet, die Bilder von Explosion, Kraft, Energie und Widerstand mit Bildern von Stille, Erschöpfung, Unbeweglichkeit verbinden, wodurch eine Präsenzwirkung kreiert wird.

11 Ginzburg: Guimarães Rosa e o terror total, S. 24.

12 Aleida Assmann: Erinnerungsräume: Formen und Wandlungen des kulturellen Gedächtnisses. München: Verlag C.H. Beck 2006.

13 Ebda., S. 289. 
In der Erzählung «A velha» («Die Greisin») werden Atmosphären auf der Oberfläche des Textes durch die Strukturierung und räumliche Bewegung materialisiert. Der Erzähler kommuniziert Temperatur- und Helligkeitsveränderungen, in Übereinstimmung mit Prosodie und auditiven Effekten, die wiederum mit bildlichen Kreationen harmonieren. Diese rufen konkrete Elemente aus Natur und Kultur hervor, die selbst als Indikatoren der historischen Zeit fungieren, wodurch ermöglicht wird, die Atmosphäre der Umgebung und die in der Erfahrung wahrgenommenen Empfindungen teilweise wiederherzustellen. Auf diese Weise werden die Auswirkungen der autobiografischen Isotopien und der Isotopien der Gemeinschaft neu dimensioniert, wodurch zentrale Themen wie Tod oder verhängnisvolles Schicksal vertieft werden. Dieses diskursive Verfahren hat den Vorzug die Wahrnehmungserfahrung zu materialisieren und durch eine enthaltene Empfindsamkeit die Möglichkeit des Sehens, Fühlens und Deutens über das intellektuelle Verständnis hinaus in der textlichen Dimension zu erzeugen.

Der vorliegende Beitrag untersucht das Vorkommen der autobiografischen Erfahrung von Guimarães Rosa in seinem Text «A velha». Als Element der Schaffung von Atmosphären und der Herstellung von Präsenz in der Erzählung wird insbesondere seine Erfahrung im nationalsozialistischen Deutschland betrachtet. Abschließend wird der ästhetische Gebrauch der "anaximandrischen These» ${ }^{14}$ analysiert, auf die in Rosas Text Bezug genommen wird und die die zugrundeliegenden Sinneffekte der Narrative potenziert und neu dimensioniert.

\section{Die Erzählung}

In «A velha» stehen sich zwei Hauptcharaktere gegenüber: Der Konsul, der während des NS-Regimes der brasilianischen Botschaft in Hamburg zugewiesen wurde und eine ältere deutsche Dame namens Verônika, die den Besuch des Diplomaten bei sich zu Hause verlangt. Nach beharrlichem Nachfragen kommt der Konsul der Bitte der alten Dame nach.

Der Grund für den Besuch klärt sich erst bei Ankunft des Konsuls in der Residenz von Dame Verônika. Die alte und kranke Frau bittet den Diplomaten um Unterstützung, um die jüdische Herkunft ihrer in Brasilien geborenen Tochter Angélika zu verheimlichen. Auf Portugiesisch offenbart die alte Dame dem Diplomaten das Geheimnis ihres Lebens: Ihre Tochter sei nicht die Tochter ihres Mannes, dem Juden Káspar Eswepp, sondern die Tochter eines brasilianischen Adligen, der die große Liebe ihres Lebens gewesen war. Verônika hatte ihn in Petrópolyis getrof-

14 Rosa: «A velha», S. 923. 
fen, als sie und ihr Mann den Hof von D. Pedro II., den ihr Mann Hebräisch lehrte, besuchten. Nachdem der Diplomat die berührende Geschichte gehört hatte, lehnte er ab, der alten Dame und ihrer Tochter zu helfen.

Die dreiseitige Erzählung aus 20 Absätzen wird von dem brasilianischen Konsul erzählt, der sich durch die Szenen der Stadt Hamburg bewegt. In ihr baut sich schrittweise die chaotische Umgebung und der Terror auf. Die ersten vier Absätze führen allgemein in die Geschichte ein. Die Zeit und der historische Kontext der Handlung werden vorgestellt. Erst ab dem fünften Absatz entwickelt sich die Handlung um Verônika, um die sich dann die Dramatik entfaltet.

Die Tragik der Geschichte offenbart sich schrittweise durch einzelne Ereignisse, in verschiedenen kleinen Szenen, die ein Mosaik aus unterschiedlichen Atmosphären ergeben. Es sind Atmosphären, die von den Textelementen gewebt werden und unter Darlegung einer pessimistischen Wahrnehmung der Situation zu einem umfassenden Bild historischer Ereignisse führen.

Die literarische Verwendung des autobiografischen und historischen Kontextes von Guimarães Rosa war bereits Forschungsgegenstand mehrerer Arbeiten. Als relevant für die vorliegende Analyse werden vor allem die Arbeiten von Jaime Ginzburg ${ }^{15}$ und Paulo Soethe ${ }^{16}$ erachtet, die sich ebenfalls mit den genannten $\mathrm{Zu}$ sammenhängen in den Deutschen Erzählungen Rosas beschäftigten.

Darüber hinaus wurden die Aussagen des Schriftstellers in einem Gespräch mit Günter Lorenz analysiert. In Rosas Äußerungen wird die Verbindung zwischen seiner Poetik und seinem Leben deutlich und dass die Vielfalt der Erfahrungen des Erlebenden Ichs im narrativen Akt nachhallt. Wie oben bereits beschrieben, bedeutet dies jedoch nicht die Reproduktion der gelebten Erfahrung, sondern es handelt sich vielmehr um Selbstreflexionen des Erlebten. Auch wenn der Autor seine Biografie nicht von seiner Arbeit trennen kann, so sind seine Arbeiten dennoch keine Autobiografie, sondern eher eine <irrationale Autobiografie» mit «irrationaler Selbstreflexion». ${ }^{17}$

[...] credo e poética são uma coisa só. Não deve haver diferença entre homens e escritores; isso é apenas uma invenção inteiramente infame dos cientistas, isso de se querer fazer dêles duas pessoas completamente diferentes. Acho isso ridículo. A vida deve fazer jus à obra e a obra deve fazer jus à vida. [...] Outras regras além dêste credo, desta poética e dêste engaja-

15 Jaime Ginzburg: Notas sobre o Diário de guerra de João Guimarães Rosa. In: Aletria: Revista de Estudos de Literatura 20/2 (2010), S. 95-107.

16 Paulo Soethe: A imagem da Alemanha em Guimarães Rosa como retrato auto-irônico. In: Scripta (PUC-Minas) 9/17 (2005), S. 287-381.

17 Günter W. Lorenz: Diálogo com Guimarães Rosa. In: Exposição do nôvo livro alemão no Brasil. Frankfurt: Otto Lembeck 1971, S. 267-311. 
mento, não existem para mim, não as reconheço. São as regras da minha vida, do meu trabalho, das minhas responsabilidades. ${ }^{18}$

Rosa äußert sich an zwei Stellen zu dem für diesen Artikel entscheidenden Punkt. Erstens betont er die Bedeutung der Literatur als mögliches Mittel für die Erlösung des Menschen, weil das Individuum in ihr seinen Charakter zeigen kann. Wenn man diese Aussage mit der Nähe zwischen Leben und Werk in Beziehung setzt, lässt sich daraus schließen, dass das Schreiben für den Autor eine transformierende Rolle im Leben des Individuums ausüben kann:

A maioria dêles, que não são verdadeiros diplomatas, mas só políticos frustrados, tomar-meá por louco. [...] Mas eu nunca poderia ser político com êste palavratório contínuo de realidade. [...] ao contrário dos «verdadeiros» políticos, acredito no homem e lhe desejo um futuro. Eu sou um escritor e penso em eternidades. O político pensa só em minutos. Eu penso na ressureição do homem. ${ }^{19}$

Die zweite Stelle stellt die Wesentlichkeit des Schreibens und des Stils in den Vordergrund, welche als Mittel zur Darstellung des Charakters des Menschen verwendet werden, sodass Sprache als Metapher für die Fähigkeit dient, mit den Menschen zu fühlen und an eine vielversprechende Zukunft zu glauben:

Pode-se fácilmente reconhecer o caráter de um homem na relação que êle tem com a língua. O caráter do homem é seu estilo, sua língua. Isto deve soar naturalmente doutrinário, mas é apenas uma verdade simples da vida. [...] eu considero língua como metáfora da sinceridade. Sinceridade e a capacidade de sentir com os homens são os fundamentos da minha crença no futuro do meu país. ${ }^{20}$

18 Ebda., S. 281. Freie Übersetzung: «Credo und Poetik sind das Gleiche. Es sollte keinen Unterschied zwischen Menschen und Schriftstellern geben. Dies ist nur eine völlig niederträchtige Erfindung von Wissenschaftlern, sie zu zwei völlig verschiedenen Personen machen zu wollen. Ich finde das lächerlich. Das Leben muss der Arbeit gerecht werden und die Arbeit muss dem Leben gerecht werden. [...] Neben diesem Credo, dieser Poesie und dieser Verpflichtung gibt es für mich keine anderen Regeln, ich erkenne sie nicht an. Das sind die Regeln meines Lebens, meiner Arbeit, meiner Verantwortung.».

19 Ebda., S. 286. Freie Übersetzung: «Die meisten von ihnen, die keine echten Diplomaten sind, sondern nur frustrierte Politiker, werden mich für verrückt halten. [...] Aber ich könnte niemals Politiker sein mit diesem unaufhörlichen Palaver über Realität. Im Gegensatz zu den «echten" Politikern glaube ich an den Menschen und wünsche ihm eine Zukunft. Ich bin Schriftsteller und denke in Ewigkeiten. Der Politiker denkt nur in Minuten. Ich denke an die Auferstehung des Menschen.»

20 Ebda., S. 287. Freie Übersetzung: «Man kann den Charakter eines Menschen in seiner Beziehung zur Sprache leicht erkennen. Der Charakter des Menschen ist sein Stil, seine Sprache. Das hört sich natürlich dogmatisch an, doch es ist nur eine einfache Wahrheit des Lebens. [...] Ich be- 
Angesichts dessen und in Anbetracht der Argumentation Assmanns können fiktive Erzählungen, selbst wenn sie nicht der objektiven Realität entsprechen, die Wahrhaftigkeit der Erfahrung des Erlebenden Ichs vermitteln. Das heißt auch, dass die Konfrontation mit Traumata oder anderen Extremsituationen in ästhetischen Arbeiten helfen kann, eine Zukunft nach einem Trauma zu ermöglichen. Die Aufrichtigkeit in der Sprache von Guimarães Rosa wird in der Erzählung in den Präsenzeffekt und in Atmosphären umgewandelt, die die Erfahrung vermitteln. Nicht mehr nur seine, sondern die einer ganzen Gemeinschaft.

Die autobiografische Dimension in den Werken von Guimarães Rosa erweitert die Interpretationsmöglichkeiten, da die poetische Kreation fiktiv bleibt. Hinzu kommen die Komponenten einer erlebten Realität. Auf diese Weise spiegelt das Schreiben nicht nur eine individuelle Erfahrung wider, sondern offenbart auch Aspekte einer gesellschaftlichen Biografie. Dieser Aspekt wird von Soethe angesprochen, der auf Ausführungen von Franz Wimmer (2001) verweist:

O exemplo de Rosa, inclusive, presta-se bem ao que Wimmer pretende com a reflexão sobre a dimensão biográfica em textos literários: encontrar na biografia pessoal tratada em literatura a via para abordar sociografias, ou seja, «biografias» de sociedades. Ao relatar nos «contos alemães» episódios de forte conotação biográfica, Rosa estaria problematizando na verdade questões da sociedade e contexto político em que vivia. ${ }^{21}$

Die Aussage Soethes, die sich an das Konzept der autobiografischen Isotopie und der Isotopie der Gemeinschaft von Ottmar Ette annähert, bestärkt den Status der Biografie als Soziografie. Sobald Umgebung und individuelle Existenz eine gewisse Homologie darstellen, findet ein Teilen von Erfahrungen statt.

In der Erzählung kann die gemeinsame Erfahrung der Lesenden, die mit dem historischen Prozess in Kontakt stehen, beobachtet werden. Soethe arbeitet die große Bewunderung Rosas für die deutsche Kultur und seine Beziehung zur Literatur in deutscher Sprache heraus. 1938, auf dem Höhepunkt der nationalsozialistischen Diktatur, übernahm Guimarães Rosa das Amt des Vizekonsuls im brasilia-

trachte Sprache als Metapher für Aufrichtigkeit. Aufrichtigkeit und die Fähigkeit, mit Menschen zusammenzuleben, sind die Grundlage meines Glaubens an die Zukunft meines Landes.»

21 Soethe: A imagem da Alemanha em Guimarães Rosa como retrato auto-irônico, S. 297. Freie Übersetzung: «Wimmers Reflexion der biografischen Dimension in literarischen Texten lässt sich gut mit dem Beispiel des Schriftstellers Rosa in Verbindung setzen: In der persönlichen Biografie, die in der Literatur behandelt wird, einen Weg zu finden, sich Soziografien, also «Biografien" von Gesellschaften, anzunähern. In den «Deutschen Erzählungen" würde Rosa an Stellen mit starker biografischer Konnotation in Wirklichkeit Fragen der Gesellschaft und des politischen Kontextes, in dem er lebte, problematisieren.» Verweis auf Franz Wimmer (2001): Identität und Perspektivität. Orientierung von Einheit. In: Rita Franchescini (Hg.): Biographie und Interkulturalität: Diskurs und Lebenspraxis. Tübingen: Stauffenburg. 
nischen Konsulat in Hamburg und blieb bis 1942, Beginn des Niedergangs des Regimes, in seinem Amt. In dieser Zeit sieht sich Rosa mit einer anderen Facette Deutschlands konfrontiert, die seine Beziehung zur deutschen Kultur verändert. Als Vizekonsul erlebte Rosa die Schrecken des Krieges und die Judenverfolgung aus der Nähe. Unter anderem entschied er selbst über das Schicksal einiger Juden, die ins Konsulat kamen und Visa beantragten, um aus Deutschland nach Brasilien $\mathrm{zu}$ fliehen.

Ein ähnlicher Gedanke wird von Ginzburg in Bezug auf die Studie von Georg Otte erwähnt. Laut ihm besteht seitens Rosa eine ambivalente Beziehung zu Deutschland selbst, in Bezug auf dessen Werte Rosa zuvor eine sehr hohe Meinung hatte, welche sich allerdings unter dem Eindruck des Nationalsozialismus änderte. $^{22}$

Rosas Interview mit Gunter Lorenz deutet darauf hin, dass der Diplomat von der Politik und auch von seinen diplomatischen Kollegen enttäuscht wurde. Daraus ergibt sich die Erkenntnis, dass politisches Handeln nicht immer in wirksames Handeln umgewandelt werden kann, ebenso wie es nicht immer möglich ist, die vom Staat begangenen Ungerechtigkeiten zu bekämpfen. Dem Individuum bleibt die Möglichkeit, der betrügerischen Realität zu entkommen und sie in Sprache umzuwandeln.

Es kann davon ausgegangen werden, dass solche Auseinandersetzungen beim Erlebenden Ich Spuren hinterlassen haben und nicht nur die Wahrnehmung der deutschen Kultur, sondern auch seine Sensibilität verändert haben. Auch Soethe ${ }^{23}$ verweist auf die Sensibilität des Schriftstellers und seine Position im historischen Prozess. Individuelle Verantwortung für Ereignisse bedeutet ihm zufolge, dass das erlebende Ich unabhängig vom Grund, sei es unterlassenes Handeln oder Zögern, eine gewisse Schuld für sein Handeln trägt. Laut Soethe erscheint diese ethische Frage explizit in Rosas deutschen Erzählungen, jedoch auch in anderen Werken:

Refina-se a sensibilidade do escritor em relação à culpabilidade essencial do homem em sua atuação histórica. E mesmo a obra-prima de Rosa, em contexto plenamente diverso, é escrita sob essa consciência pessoal e social: Riobaldo, jagunço que se torna fazendeiro, narra sobretudo a própria culpabilidade pela perda de Diadorim, seja por omissão, seja pela hesitação às vezes calculada em dedicar-se plenamente às causas de seu amor. ${ }^{24}$

22 Ginzburg: Notas sobre o Diário de guerra de João Guimarães Rosa, S. 107.

23 Soethe: A imagem da Alemanha em Guimarães Rosa como retrato auto-irônico.

24 Ebda., S. 297. Freie Übersetzung: «Der Schriftsteller zeigt sich sensibler in Bezug auf die wesentliche Schuld der Menschheit in ihrem historischen Handeln. Sogar Rosas Meisterwerk Grande sertão: veredas steht unter diesem persönlichen und sozialen Bewusstsein: Riobaldo, ein Jagunço (paramilitärische Arbeit), der Landwirt wird, erzählt vor allem von seiner eigenen Schuld am Ver- 
Der pessimistische Tonfall und die Schuldfrage sind Aspekte die es ermöglichen, in «A velha» die Erwähnung einer sanaximandrischen These` zu verstehen, die im nächsten Abschnitt der vorliegenden Arbeit vorgestellt wird.

In dieser Kurzgeschichte wird die Sinneserfahrung, die das Erlebende Ich durch das Erzählende Ich teilt, auf textueller Ebene durch die pessimistische Atmosphäre materialisiert. Letztere ergibt sich aus dem politischen Kontext und den Zwängen des Staates, welche ein gerechtes Handeln erschweren. Die Textqualität, die es dem Lesenden ermöglicht, Erfahrungen in seiner physischen Dimension zu sammeln und zu erleben, wird durch die Textkomponenten erzeugt, die sich auf die fünf Sinne beziehen. Sie sind entscheidend für die Erzeugung des Präsenzeffekts und strahlen Sensibilität im Text aus, wie von Ottmar Ette hervorgehoben wurde.

Letztendlich ermöglicht die Literatur für Rosa die Figuration und den Erfahrungsaustausch und damit die Möglichkeit einer Zukunft, die aus der Reflexion des Lebens und der Ereignisse entsteht. Somit ist die Untrennbarkeit von Erinnerung, Erfahrung und Narrative, die mit ästhetischer Umdeutung eine Atmosphäre der historischen Zeit konstruieren und unbewusste Soziografien und Historiografien widerspiegeln, gewährleistet. Diese wiederum werden durch autobiografische Isotopien und Isotopien der Gemeinschaft wahrgenommen und durch den Stil der Narration verwirklicht.

\section{Die anaximandrische These}

Guimarães Rosas Beziehung zu Deutschland verändert sich seit seiner Konfrontation mit dem Schrecken und den Einschränkungen durch den Nationalsozialismus und den eigenen Erfahrungen angesichts des Krieges. Die pessimistische Atmosphäre der Geschichte zeigt das Bewusstsein, dass Menschen in ihren Handlungen unabhängig von ihren Idealen eingeschränkt sind, was dazu führt, dass der Autor sich mit der Unaufhaltsamkeit des Schicksals auseinandersetzt.

Die anaximandrische These wird sowohl in der Produktion der pessimistischen Atmosphäre als auch im eigentlichen Aufbau der Geschichte angewandt. Es gibt außerdem Überlappungen verschiedener textueller Dimensionen: der thematischen Ebene, des ästhetischen Schaffens und der Autobiografie.

Die Erwähnung der aximandrischen These in der vorliegenden Erzählung kann als eine Karte des Weges interpretiert werden, den der Erzähler zurückgelegt hat; ein Kreis, der mit dem Titel «A velha» beginnt und mit «A longa mulher. O sistema

lust von Diadorim, durch unterlassene Handlung oder durch Zögern, sich ganz seiner Liebe hinzugeben.» 
do mundo. A velha vida» («Die lange Frau. Die Weltordnung. Das alte Leben») ${ }^{25}$ endet. Das ist die Karte, von deren Weg man nicht abweichen kann, vor allem «frente ao caos e ao espírito de catástrofe» («angesichts des Chaos und des Geistes der Katastrophe»). ${ }^{26}$ Der Konsul stößt im Laufe seines Lebens auf das Finitum der Menschen und ihrer unproduktiven Handlungen angesichts der brutalen Auferlegung. Ihnen bleibt nur übrig, in einem tot-lebendigen Zustand zu verweilen. «Todos nós jazíamos de pé, em volta dela» («Alle standen wir zu ihren Füßen um sie herum»). ${ }^{27}$ Im folgenden Auszug bezieht sich Rosa auf die anaximandrische These:

[...] es starben viele Vögel. War das Herz dieser Natur sanft, war es bösartig? Einer fühlte sich, in so unerbittlichen Zeiten, auf der Mitte dieser Brücke, als ob er mit dem Antlitz des Chaos und des Geistes der Katastrophe konfrontiert sei, er stehe dem letzten Ermessen in der anaximandrischen Theorie gegenüber - der Sünde, geboren zu werden. Jeder von uns ist, trotz allem, Teil des Lebens. ${ }^{28}$

In seiner Äußerung kann man spüren, dass der Tod ein unumgängliches Schicksal aller Lebewesen ist. Das heißt, dass Vögel und Menschen das gleiche Ende nehmen. Dies sind die Funktionsparameter der Welt, die die definierten Grenzen durch die periodische Abfolge der Dinge festlegen. Mit anderen Worten muss etwas vergehen, damit etwas Neues entstehen kann; der Tod ist also der Preis, den man zahlen muss, um zu existieren. Das ist das Gesetz der Natur, das von Anaximander formuliert wurde. In der Erzählung wird das Gesetz durch Totalitarismus in Gang gesetzt und Schicksalsschläge sind vorhergesehen, was letztendlich die Begrenzung der individuellen Handlungen bedeutet, sei es um einzugreifen oder um den Geschichtsprozess, der sich in diesen schwierigen Zeiten angesichts des totalitären Regimes etabliert, zu wenden.

Bertrand Russell ${ }^{29}$ erläutert, dass das Gesetz der Zeit in Anaximanders Denken auf der Idee basiert, dass alles aus einer unendlichen, ewigen und zeitlosen Substanz kommt, die alle Welten, alle Dinge, die daraus entstehen, umhüllt. Diese Substanz regelt alles. Durch sie wird alles lebendig und muss zu ihr zurück-

25 Rosa: «A velha», S. 923. Man beachte, dass im Original die Worte des Titels («A velha») sich im letzten Satz des Textes genau wiederholen: «A velha vida.» Nach der durchdachten Wiederholung folgt nur «vida», das Leben.

26 Ebda.

27 Ebda., S. 923.

28 Ebda., S. 923. Im Original: «[...] morriam muitos pássaros. O coração daquela natureza era manso, era mau? Sentia-se um, ao meio de tal ponte, à face do caos e espírito de catástrofe, em tempo tão ingeneroso, ante o critério último - o pecado de nascer - na tese anaximândrica. Todos pertencíamos, assim mesmo, à vida.»

29 Bertrand Russell: História da Filosofia Ocidental. São Paulo: Companhia Editora Nacional 1957. 
kommen. Das ist das kosmische Gesetz. Nach Anaximander besteht die einzige Form der Erlösung der individuellen Existenz in der Vernichtung des Lebens, da es den Kosmos in Unruhe versetzt. Daher wird das Leben als eine Ungerechtigkeit betrachtet, die einer Korrekturmaßnahme der Zeit erliegen muss. Nietzsche fasst diesen Gedanken wie folgt zusammen:

«Woher die Dinge ihre Entstehung haben, dahin müssen sie auch zu Grunde gehen, nach der Nothwendigkeit; denn sie müssen Buße zahlen und für ihre Ungerechtigkeiten gerichtet werden, gemäß der Ordnung der Zeit». Rätselhafter Ausspruch eines wahren Pessimisten, Orakelaufschrift am Grenzsteine griechischer Philosophie, wie werden wir dich deuten ${ }^{30}$

Die eigenartige Interpretation des Gedankens von Anaximander durch Nietzsche dient am besten zum Entschlüsseln der Phrase in Rosas Text: «ante o critério último - o pecado de nascer - na tese anaximândrica» («er stehe dem letzten Kriterium in der anaximandrischen Theorie gegenüber - der Sünde, geboren zu werden») ${ }^{31}$. Denn Nietzsche interpretiert den Ursprung anders als andere Kommentatoren, indem er annimmt, dass die wesentliche Frage nach Herkunft und Endlichkeit für Anaximander auch moralisch und nicht nur physisch ist. Wenn es einerseits die bestimmten Eigenschaften der Wesen sind, die sie zum Erliegen bringen, dann ist es genau die Unbestimmtheit der ursprünglichen Substanz, die ihre Unsterblichkeit erlaubt. Der Niedergang der ursprünglichen Einheit erfolgt jedoch widersprüchlich durch die Ablehnung der Pluralität und Unbestimmtheit. Das ethische Problem besteht genau in dem Paradoxon, dass die Pluralität aus der Summe der Ungerechtigkeiten entsteht, für die zu büßen ist, und dass der Mensch bei der ständigen Suche nach dem Werden nicht mehr die ursprüngliche Einheit darstellt.

[W]ie ist doch, wenn es überhaupt eine ewige Einheit giebt, jene Vielheit möglich? und entnimmt die Antwort aus dem widerspruchsvollen, sich selbst aufzehrenden und verneinenden Charakter dieser Vielheit. Die Existenz derselben wird ihm zu einem moralischen Phänomen, sie ist nicht gerechtfertigt, sondern büßt sich fortwährend durch den Untergang ab. [...] Woher der immer erneute Strom des Werdens? [...] das ewige Werden kann seinen Ursprung nur im ewigen Sein haben, die Bedingungen zu dem Abfall von jenem Sein zu einem Werden in Ungerechtigkeit sind immer die gleichen, die Constellation der Dinge ist nun einmal so beschaffen, daß kein Ende für jenes Heraustreten des Einzelwesens aus dem Schooß des «Unbestimmten» abzusehen ist. Hierbei blieb Anaximander [...] Je mehr man dem Probleme sich nahen wollte, wie überhaupt aus dem Unbestimmten je das Bestimmte, aus dem Ewigen das Zeitliche, aus dem Gerechten die Ungerechtigkeit, durch Abfall entstehen könne, um so größer wurde die Nacht. ${ }^{32}$

30 Friedrich Nietzsche: Die Philosophie im tragischen Zeitalter der Griechen. (o. D.) Online verfügbar unterhttp://www.nietzschesource.org/\#eKGWB/PHG. Letzter Zugriff: 10.05.19.

31 Rosa: «A velha», S. 923.

32 Nietzsche: Die Philosophie im tragischen Zeitalter der Griechen. 
Anaximander kann in der Physik keine Antwort finden, er findet Zuflucht im metaphysischen Schutzraum und in der Wahrnehmung der Endlichkeit der Wesen und allem, was in der Welt existiert. Wenn es keine logische Antwort gibt, bleibt $\mathrm{zu}$ akzeptieren, dass alles endlich ist.

\begin{abstract}
Was ist euer Dasein werth? Und wenn es nichts werth ist, wozu seid ihr da? Durch eure Schuld, merke ich, weilt ihr in dieser Existenz. Mit dem Tode werdet ihr sie büßen müssen. Seht hin, wie eure Erde welkt; die Meere nehmen ab und trocknen aus [...]; das Feuer zerstört eure Welt bereits jetzt, endlich wird sie in Dunst und Rauch aufgehn. Aber immer von Neuem wieder wird eine solche Welt der Vergänglichkeit sich bauen: wer vermöchte euch vom Fluche des Werdens zu erlösen ${ }^{33}$
\end{abstract}

Durch die häufig verwandte Interpretation des Schicksals als Korrekturmaßnahme der Zeit ließe sich eine indirekte Beziehung zum politischen Kontext herstellen, da das Scheitern dieser These das Ergebnis einer fehlenden ursprünglichen Einheit ist. Nietzsches Interpretation weist jedoch in die entgegengesetzte Richtung, da der Tod nicht durch die Zerstörung der Einheit und einer reinen ursprünglichen Substanz entsteht. Im Gegenteil: Es kommt zu einer Unterbrechung durch Suche nach Einheit.

In der Erzählung wird das Gesetz der Zeit durch den Totalitarismus in Bewegung gesetzt; wie Ginzburg ${ }^{34}$ erklärt, wird das Unglück erwartet. Er zitiert Hannah Arendt, die meint: «Unter den Bedingungen des totalen Terrors kann nicht einmal die Angst das Verhalten des Bürgers leiten, weil der Terror seine Opfer unabhängig von Handlungen oder individuellen Gedanken wählt.. ${ }^{35}$ Woraus Ginzburg sich auf Arendt beziehend schließt: «o regime totalitário [...] procura atribuir movimento à natureza e à história, em nome de uma unidade da humanidade.» ${ }^{36}$

In «A velha» sieht sich der Diplomat mit Chaos und Katastrophe konfrontiert. Es liegt an ihm, Entscheidungen zu treffen. Aber obwohl er Gutes tun könnte, hat er als Einzelperson keine Möglichkeit, gegen die vom Staat begangenen Ungerechtigkeiten anzukommen. Als er dem Unglück ins Auge sieht, erwirbt er das Bewusstsein des Skeptikers, da er kein «cooperador passivo do destino» (passiver Helfer des Schicksals) ${ }^{37}$ ist oder werden will. Er muss die anaximandrische These akzeptieren und sich «o sistema do mundo. A velha vida» («der Weltordnung, dem alten Leben») ${ }^{38}$ unterordnen.

33 Ebda.

34 Ginzburg: Guimarães Rosa e o terror total, S. 17-27.

35 Hannah Arendt: Origens do totalitarismo. São Paulo: Companhia das Letras 1989, S. 519-520.

36 Ginzburg: Guimarães Rosa e o terror total, S. 25.

37 Rosa: «A velha», S. 923.

38 Ebda. 
So kann die Passage, die in der Kurzgeschichte zitiert wird, als eine erste Antwort auf das tödliche und unerbittliche Schicksal verstanden werden, das von Anaximander beschrieben und vom totalitären Regime in Gang gesetzt wurde: Jeder von uns ist, trotz allem, Teil des Lebens.

\section{Die Produktion von Stimmung}

Die pessimistische Atmosphäre in der Erzählung «A velha» wird durch die Kommentare des Erzählers zu seiner Wahrnehmung der Umgebung kreiert und nicht primär durch Überlegungen. Die Kommunikation von klimatischen Veränderungen, von Geräuschen und Gerüchen gibt der textuellen Oberfläche eine Sinnlichkeit, die in der Lektüre zu einer kinästhetischen Wirkung führt. Außerdem stellen kulturelle Zeichen und Zeichen der Natur den historischen Moment wieder her. Diese textuellen Elemente produzieren die fiktive Welt und reproduzieren bis $\mathrm{zu}$ einem gewissen Punkt die Atmosphäre des historischen Moments ohne die Notwendigkeit, den unterschwelligen Sinn zu vermitteln. Das Gefühl, das durch den Präsenzeffekt in der Erzählung freigesetzt wird, erscheint sowohl in der Atmosphäre, als auch in der Materialisierung der Umgebung. Die Gefühle des geschichtlichen Kontextes werden gezeigt und der unterschwellige Sinn der Narrative ans Licht gebracht. Seien es faktische, historische Ereignisse, oder sogar die Biografie des Autors.

Nach Gumbrecht trägt die Beschäftigung mit dem Präsenzeffekt dazu bei, das narrative Potenzial zu heben, was dem Leser erlaubt, in die Welt der Sinnlichkeit, d.h. in Welten, die der physischen Umgebung gleichen, ${ }^{39}$ einzutreten. Die Lektüre der Stimmung zielt nicht darauf ab, die den Narrativen zugrundeliegenden Sinnebenen zu offenbaren. Gumbrecht trennt jedoch die ästhetische und die historische Erfahrung nicht. Für ihn ermöglicht das Betonen der Stimmung die Erhaltung der Kraft der Literatur in ihrer Ganzheit. Gumbrecht führt hierzu Folgendes aus:

A palavra «presença» não se refere [...] a uma relação temporal. Antes, refere-se a uma relação espacial com o mundo e seus objetos. Uma coisa «presente» deve ser tangível por mãos humanas - o que implica, inversamente, que pode ter impacto imediato em corpos humanos. ${ }^{40}$

39 Hans Ulrich Gumbrecht: Atmosfera, ambiência, Stimmung: sobre um potencial oculto da literatura. Tradução de Ana Isabel Soares. Rio de Janeiro: Contraponto: Ed. PUC-Rio 2014, S. 96.

40 Hans Ulrich Gumbrecht: Produção de presença: o que o sentido não consegue transmitir. Tradução de Ana Isabel Soares. Rio de Janeiro: Contraponto: Ed. PUC-Rio 2010, S. 13-14. Freie Über- 
In der Erzählung ist der Präsenzeffekt insofern gegeben, als der Erzähler sich durch den Raum bewegt und seine Wahrnehmung der Umgebung und der ihn umgebenden Sozialstrukturen kommuniziert. Er materialisiert sie durch Zeichen, Bilder und Symbole, die Referenzillusionen der Weltbilder komponieren. Die kulturellen und natürlichen Elemente in der Umgebung zeigen die ihn umgebenden Sozialstrukturen, die die Wahrnehmung des Erzählers beeinflussen und verwandeln. Er setzt diese Strukturen in Narrative um, wenn er die Gefühle von klimatischen Ereignissen, Temperaturen, Helligkeit und Klängen wiedergibt, die für den Präsenzeffekt der Umgebung verantwortlich sind.

Nach Gumbrecht existieren die Texte in ihrer textuellen Dimension unabhängig von dem Paradigma der Darstellung außerhalb der Sprache. Obwohl der Text mit vielen Realitäten verbunden werden kann, existiert er nur in der konkreten Realisierung auf dem Blatt Papier. Mehr noch: in der durch den Lesenden durchgeführte Aktualisierung. Am Ende werden die Atmosphäre und die Produktion des Präsenzeffekts durch die Sprache und ihre textuellen Komponenten materialisiert. Gumbrecht ${ }^{41}$ meint, dass weder die Atmosphäre, der Ton, noch die Stimmung selbständig existieren können. Der Erfolg der Realisierung hängt im Gegenteil von den materiellen Komponenten der Werke ab.

\begin{abstract}
»Ler com a atenção voltada ao (sic) Stimmung» sempre significa prestar atenção à dimensão textual das formas que nos envolvem, que envolvem nossos corpos, enquanto realidade física - algo que consegue catalisar sensações interiores sem que questões de representação estejam necessariamente envolvidas. [...] Sem exceção, todos os elementos que contêm textos podem contribuir para produzir atmosferas e ambientes, o que significa que obras ricas em Stimmung não terão de ser primordialmente - e, com certeza, não exclusivamente - de natureza descritiva. ${ }^{42}$
\end{abstract}

Die in der Erzählung dominante Atmosphäre verweist auf die Einschränkungen durch den historischen Kontext und den abgegrenzten Raum, in denen die Figu-

\footnotetext{
setzung: «Das Wort 〈Präsenz〉 bezieht sich nicht auf ein zeitliches, sondern auf ein räumliches Verhältnis zur Welt und zu deren Objekten. Was «präsent` ist, soll für Menschenhände greifbar sein, was dann wiederum impliziert, dass es unmittelbar auf menschliche Körper einwirken kann.»

41 Gumbrecht: Atmosfera, ambiência, Stimmung, S. 14.

42 Ebda., S. 14. Freie Übersetzung: « 〈Lesen mit Aufmerksamkeit für die Stimmung〉 bedeutet immer, auf die Textdimension der uns umgebenden Formen zu achten, die unseren Körper als physische Realität einbeziehen - etwas, das innere Empfindungen katalysieren kann, ohne dass dabei Repräsentationsfragen betrachtet werden müssen. [...] Alle textuellen Elemente können ausnahmslos dazu beitragen, Atmosphären und Umgebungen zu erzeugen, was bedeutet, dass stimmungsreiche Werke nicht primär - und sicherlich nicht ausschließlich - einen deskriptiven Charakter haben müssen.»
} 
ren die Konfrontation mit einem fatalen Schicksal und die Einschränkung der Menschen angesichts des Totalitarismus erleben. Gumbrecht sagt hierzu:

\begin{abstract}
Existe uma relação entre certas formas de narração e determinadas atmosferas específicas [...] Veja-se o caso de Morte em Veneza, de Thomas Mann. [...] O livro é mesmo a evocação de uma decadência fin-de-siècle, em toda a sua complexidade - em nuances, odores, cores, sons e, acima de tudo, nas dramáticas alterações do clima atmosférico, que tanta fama deram a essa obra. Em outras palavras [...], o que de mais fascinante há nesse livro é uma atmosfera específica que só pode ser experimentada numa consciência historicamente específica da presença da morte em vida. ${ }^{43}$
\end{abstract}

Für Gumbrecht ${ }^{44}$ wird der Präsenzeffekt durch Wahrnehmung der materiellen Umgebung erzeugt, einschließlich der Beschreibungen und Kommentare über die physische Dimension von Phänomenen, die ästhetisch verknüpft werden und in der textuellen Dimension auftreten. Der Präsenzeffekt ist verantwortlich dafür, die Lesenden mit den verschiedenen Ebenen des Textes zu verbinden.

\title{
Die Atmosphäre des Pessimismus
}

Die Erzählung besteht aus vier unterschiedlichen Handlungsmomenten. Der erste Moment, in dem der Name Frau Wetterhuses erwähnt wird, besteht aus einem einzigen Absatz. Genauso verhält es sich mit dem zweiten Moment, im Konsulat, und mit dem dritten, in dem der Name der alten Dame wiederholt wird. Im letzten Moment herrscht die pessimistische Atmosphäre vor, da setzt sich die anaximandrische These durch.

Der implizite philosophische Sinngehalt und die drückende Atmosphäre etablieren sich zeitgleich. Das Bewusstsein für die Einschränkung des individuellen Handelns führt zur Annahme der Parameter, die in der damaligen Zeit im Umlauf waren. Gerade die kinästhetischen Elemente im Text realisieren diese potenzielle Erfahrung und werden vom Lesenden durch das Erfassen des Sensiblen wahrgenommen, während der Erzähler sich durch die Topographie bewegt und

43 Ebda., S. 14-15. Freie Übersetzung: «Es gibt einen Zusammenhang zwischen bestimmten Erzählformen und bestimmten spezifischen Atmosphären. [...] Z. B. Der Tod in Venedig von Thomas Mann [...]. Das Buch ist auch die Anspielung auf eine fin-de-siècle-Dekadenz in all ihrer Komplexität. Es sind die Nuancen, Gerüche, Farben, Klänge und vor allem die dramatischen Veränderungen des atmosphärischen Klimas, die dieser Arbeit so viel Ruhm verliehen haben. Mit anderen Worten, das Faszinierendste in diesem Buch ist eine spezifische Atmosphäre, die nur in einem historisch spezifischen Bewusstsein der Gegenwart des Todes im Leben erlebt werden kann.» 44 Ebda., S. 16. 
auf Objekte und Wesen der Welt trifft, um ihre Eindrücke und Empfindungen wiederzugeben. Die Atmosphäre wird durch die empirische und ikonische Erfassung der Signifikanten aufgebaut, durch das, was der Erzähler in seiner Umgebung sieht, hört und fühlt. Unter anderen textuellen Elemente, die für die Präsenz verantwortlich sind, fällt die Topologie auf ${ }^{45}$, da die Dynamik, die durch die Bewegung des Erzählers erzeugt wird, erlaubt, dass das Potenzial des Präsenzeffekts die innere und äußere, kollektive und individuelle Atmosphäre umfasst.

$\mathrm{Zu}$ Analysezwecken wurden eine Reihe von Szenen ausgewählt, die dem Verlauf der Atmosphäre und dem ursprünglichen Ambiente der drei vom Erzähler abgedeckten Räume, nämlich der diplomatischen Umgebung, der Straße und dem Haus der alten Dame, entsprechen.

In den folgenden Abschnitten werden drei verschiedene Szenen betrachtet, die im privaten und diplomatischen Umfeld ein allgemeineres Bild für die Zusammensetzung der Atmosphäre darstellen:

Eine sehr alte und kranke Frau bat den Konsul zu sich nach Hause, ihres letzten Willens wegen. Frau Wetterhuse.

Die Bitte verlor sich als abstrakte Verpflichtung im alltäglichen Durcheinander der Fälle. Das Konsulat wurde von Juden überrannt, die, zermahlen von Angst, nach der Ausreise hungerten, von lang anhaltendem Schaudern erfüllt und getäuscht, ihr Leid öffentlich zur Schau stellten, und auf jedem Gesicht sah man die Erwartung, dass als letzte Hoffnung nur der Selbstmord blieb. Sah man sie, musste man an Hitlers Stimme im Radio denken - rau, wutrasend. Seit November war ihre Verfolgung noch grenzenloser und erbarmungsloser, sie hatte ein brutales Ausmaß angenommen. Käme der Krieg, wäre der erste Befehl sie zu töten $?^{46}$

45 D. V. de Aguiar: Planta e corpo: elementos de topologia na arquitetura. Vitruvius. 9 mar. 2009. Online verfügbar unter http://www.vitruvius.com.br/revistas/read/arquitextos/09.106/70. Letzter Zugriff: 09.07.18. «É sabido da experiência que a ordem topológica define características espaciais que tornam o espaço arquitetônico ou mais ou menos inteligível ao usuário. Todo e qualquer arranjo espacial produzido pelo homem conterá um inerente sistema de rotas que dará suporte à imensa variedade de programas/eventos que constituem a vida humana.» Freie Übersetzung: «Aus Erfahrung weiß man, dass die topologische Reihenfolge die räumlichen Eigenschaften definiert, die den architektonischen Raum für den Benutzer mehr oder weniger verständlich machen. Jede von Menschen gemachte Raumanordnung wird ein inhärentes System von Routen enthalten, das die immense Vielfalt von Programmen/Ereignissen unterstützen wird, die das menschliche Leben ausmachen.»

46 Rosa: «A velha», S. 921. Im Original: «Uma senhora, muito velha e doente, pedia que o Cônsul lhe fosse à casa, para assunto de testamento. Frau Wetterhuse. O recado se perdia, obrigação abstrata, no tumulto diário de casos, o Consulado invadindo-se de judeus, sob mó de angústias, famintos de partir, sofridos intenso, em desengano, público pranto e longo estremecer, quase cada rosto prometendo-se a coativa esperança final do suicídio. Vê-los, vinha à mente a voz de Hitler 
In der ersten Szene sind die Figur Frau Wetterhuse und die private Umgebung ihrer Behausung noch abstrakte Räume. Diese Räume stehen im Gegensatz zum Umfeld, das zum Zeitpunkt des Kommentars erlebt wird, denn der private Raum, ist scheinbar vor der politischen und öffentlichen Unruhe geschützt, sodass sich in ihm ein individuelles und privates Problem entwickeln kann.

In der zweiten Szene sind die Figuren der Konsul und die Juden im Konsulat, ein Ort, der durch die diplomatische Funktion definiert und abgegrenzt ist. Die initiale Ruhe widerspricht der Unruhe, die schrittweise und hyperbolisch durch die Reihenfolge von Adjektiven etabliert wird: «famintos» («nach der Reise hungerten»), «intenso» e «longo» ${ }^{47}$ («von lang anhaltendem Schaudern erfüllt und getäuscht»). Am Ende der letzten Szene wird die Umgebung vom Pessimismus dominiert, der zu Hoffnungslosigkeit führt: «quase que cada rosto prometendo-se a coativa esperança final do suicídio» («und auf jedem Gesicht sah man die Erwartung, dass als letzte Hoffnung nur der Selbstmord blieb»).

In dieser Szene wird die Atmosphäre genauso wie zuvor aufgebaut. Am Ende des Ausschnitts dringt Hitlers Stimme im Radio in die Szene ein: «Hitler ao rádio rouco, raivoso» ${ }^{48}$ («Hitlers Stimme im Radio - rau, wutrasend»). Die Alliteration von dem Phonem «r» evoziert einen wütenden Klang und bewirkt die Verbindung zwischen Tonproduktion und Gefühl. Die aspirierte Aussprache von «h» in «Hitler» ist im Portugiesischen der Aussprache des Phonems «r» gleich, sodass sich in dieser Sprache die Alliteration nicht nur im Buchstaben «r» realisiert, sondern auch im «h» des Namens «Hitler». ${ }^{49}$ Ebenfalls signifikant ist, dass wegen der Alliteration und graphischen Wiederholung von «r» mit der lexikalischen Auswahl von «rouco» und «raivoso» zwei Wörter aus unterschiedlichen Wortfeldern verbunden wurden: Das Wortfeld der akustischen Beschreibung der Stimme, und das Wortfeld, das mit der emotionalen Charakterisierung des politischen Führers zusammenhängt. Der Ausschnitt zeigt, wie die Atmosphäre des Hasses allmählich materialisiert wird: Sowohl innerhalb des Textes, mit den Stilmerkmalen, die performativ werden, als auch mit Blick auf die damalige deutsche Gesellschaft. Hier

ao rádio - rouco, raivoso. Contra esses, desde novembro, se implacara mais desbordada e atroz a perseguição, dosada brutal. Viesse a guerra, a primeira ordem seria matá-los?»

47 Ebda., S. 921.

48 Ebda., S. 921.

49 Soethe: Os humores de Wotan: fontes alemãs de Guimarães Rosa, S. 235. Laut Soethe wurde diese Charakterisierung Hitlers 1940 von Guimarães Rosa während seiner Jahre in Hamburg in einem seiner Hefte «Studien für das Werk» geschrieben: «Ao rádio, Hitler, rouco e raivoso, rolando os erres», die mit einigen Veränderungen 21 Jahre später bei der analysierten Erzählung verwendet wurde. Auch nach Soethe befindet sich in den gleichen Notizen der Neologismus «hitlerocidades», der ebenfalls in der Erzählung eingesetzt wurde. 
wirkt die Performanz von Hitlers Stimme, die im «Radio» als Medienunterstützung verbreitet wird, in dem «rouco» und «raivoso» widerhallen und politische Effizienz gewinnen.

In diesem Sinn zeigt die Erzählung zunächst die voranschreitende und unmenschliche Verfolgung von Juden: «Contra esses, desde novembro, se implacara mais desbordada e atroz a perseguição, dosada brutal» («Seit November war ihre Verfolgung noch grenzenloser und erbarmungsloser, sie hatte ein brutales Ausmaß angenommen»). ${ }^{50}$ Danach erreicht die Sequenz ihren Höhepunkt in der Möglichkeit, Leben zu vernichten: «Viesse a guerra a primeira ordem seria matá-los?» («Käme der Krieg, wäre der erste Befehl sie zu töten?»). ${ }^{1}$ Der Verweis auf den Massenmord zeigt, dass der Erzähler nicht mit Gerechtigkeit rechnet und intensiviert gleichzeitig die Atmosphäre der Hoffnungslosigkeit.

In diesem Kontext erlöschen Frau Wetterhuses Name und Bitte unter den Tränen und den Nebeln, die Norddeutschland bedecken. Die beharrliche Bitte der Frau führt den Protagonisten in eine neue und offene Umgebung. Die Atmosphäre an diesem offenen Ort wird durch die Wahrnehmung von natürlichen Elementen, kulturellen Zeichen und der Temperatur etabliert. Der Konsul verlässt nach kontinuierlichen Anfragen das Konsulat und geht in Richtung von Frau Wetterhuses Haus. Zwischen dem Konsulat und dem Haus gibt es den gerade vom Wetter bestimmten, äußeren Raum. Als der Erzähler das Konsulat verlässt, sagt er, dass es kalt war «fazia todo o frio» («die Kälte war überwältigend»).

Die schöne, große Hansestadt versank im nachtdunklen Tag, nicht einmal ihr Himmel aus flüssigem Stahl und die Umrisse der fünf Türme aus grünspanigem Kupfer waren sichtbar. Wie dünne, eisige Peitschen, die an Schlangenschwänze erinnerten, blies der beißende Wind, während der Schnee in dicken Flocken fiel. Als ich auf den Glockengießerwall trat, musste ich mich, obgleich dick in Kleidung gehüllt, der beißenden Kälte und der durchdringenden Nässe entgegenstellen. ${ }^{52}$

Die Straße steht aufgrund der Abwesenheit von Menschen, der Stille und der Konzentration auf die Temperatur im klaren Gegensatz zur Topographie des Konsulats. Die Erzählersicht fokussiert auf die natürlichen, kulturellen und ikonischen Elementen und zu dem kalten nächtlichen Wetter der Stadt.

50 Ebda., S. 921.

51 Ebda., S. 921.

52 Ebda., S. 921. Im Original: «Sumia-se no dia noturno a bela, grande cidade hanseática, nem se avistavam seu céu de ferro molhado e as silhuetas das cinco igrejas, suas torres de cobre em azinhavre. Dava-se, que nem caudas de cobras, delgados glaciais chicotes - nevando, fortes flocos - o vento mordaz. Saindo para o Glockengiesserwall, se bem que abafado em roupas, eu tivera que me enregemer, ao resfrio cravador e à umidade, que transia.» 
Die nächtliche und düstere Stimmung verdeckt die Schönheit der Stadt und man kann weder den Himmel, der von «flüssigem Stahl» verdeckt wird, noch die «Umrisse der fünf Türme aus grünspanigem Kupfer» sehen. Der Erzähler erinnert sich jedoch an die Kupfertürme, die durch die Wirkung der Zeit von Oxidation bedeckt sind. Die ikonische Schönheit der Vergangenheit ist unter der nächtlichen Atmosphäre verborgen. Das von der Szene geweckte Gefühl ist Trostlosigkeit, die zum Bild von einer sich zersetzenden Umgebung führt. Die Umgebung wird vom Gesetz der Zeit erodiert, dem alles unterliegt, seien es Gegenstände, seien es Lebewesen.

Das Landschaftsbild wird unsichtbar, die Sicht ist eingeschränkt, sodass es unmöglich ist, andere Horizonte als die Realität der nächsten Umgebung zu betrachten. Die Sicht wird durch das taktile Gefühl ersetzt, das im Körper des Erzählers wirkt. Die Kälte ist schmerzhaft, die Schneeflocken und der Wind sind scharf, berühren den Körper mit besonderer Kraft, weswegen das Gefühl als «beißend» beschrieben wird. Die Kälte und die Feuchtigkeit durchdringen die Kleidung des Erzählers, treffen seine Haut, was dazu führt, dass er aufstöhnt: «enregemer». ${ }^{53}$ In der unmittelbaren Umgebung erscheint ein anderes Symbol, «das Hakenkreuz», das beim Erzähler im zum Teil bereits bekannten Zitat Ironie auslöst:

An jeder Ecke sah man das Zeichen: in einem Kreis sitzend, in den schräg die Swastika passte, der Adler mit ausgebreiteten Flügeln. Draußen die Schatten der Baumstämme im Schnee und die kreisenden Raben, der Unglücksrabe. Man sagte, dass dies der härteste Winter seit Jahren sei, mit weit mehr Frost, als gewöhnlich: es starben viele Vögel. War das Herz dieser Natur sanft, war es bösartig? Einer fühlte sich, in so unerbittlichen Zeiten, auf der Mitte dieser Brücke, als ob er mit dem Antlitz des Chaos und des Katastrophengeistes konfrontiert sei, er stehe dem letzten Ermessen in der anaximandrischen Theorie gegenüber - der Sünde, geboren zu werden. Jeder von uns ist, trotz allem, Teil des Lebens. ${ }^{54}$

In der unmittelbaren Umgebung wird das Hakenkreuz, das den Raum ausfüllt, sich dem Auge aufdrückt und die Wahrnehmung einschränkt, bald zum Hauptfokus des Sichtbaren. In der Beschreibung des Symbols betont der Erzähler die Anwesenheit des Adlers mit offenen Flügeln, die innerhalb eines begrenzten Kreises angeordnet sind, was ironischerweise als Schutz interpretiert werden kann.

53 Guimarães Rosa schafft einen Neologismus, denn der Ton und die Schreibweise von «enregemer» ist mit Versteifen («enrijecer») und Stöhnen («gemer») verbunden.

54 Ebda., S. 921. Im Original: «Via-se, a cada canto, o emblema: pousada num círculo, onde cabia oblíqua a swástika, a águia de abertas asas. A fora, as sombras dos troncos de árvores, na neve, e as curvas dos corvos, o corvo da desdita. Dizia-se que, este, muitos anos faz, seria o mais duro inverno, de concumulados gelos: morriam muitos pássaros. 0 coração daquela natureza era manso, era mau? Sentia-se um, ao meio de tal ponte, à face do caos e espírito de catástrofe, em tempo tão ingeneroso, ante o critério último - o pecado de nascer - na tese anaximândrica. Todos pertencíamos, assim mesmo, à vida.» 
Der Adler widersetzt sich der Flucht des Raben, Bote noch dunklerer Zeiten. Außer dem Emblem kann neben den Schatten der Baumstämme im Schnee wenig wahrgenommen werden; Nicht einmal die Stämme sind sichtbar, nur ihre Schatten.

Die «unerbittliche» Zeit kann sowohl auf die historische Zeit («tempo») als auch auf das Wetter (im portugiesischen ebenso «tempo») Bezug nehmen, weil der Winter desjenigen Jahres für den härtesten seit Langem gehalten wurde und mit dem Tod vieler Vögel (Lebewesen wie Menschen) verbunden wird.

Aus dieser Bemerkung des Erzählers ergibt sich die Frage: Ist die Natur gut oder schlecht? Hätte sie angesichts der Katastrophe Stellung bezogen, oder war es nur das anaximandrische Gesetz der Zeit, das aufgrund der durch den Totalitarismus verursachten Störung in Gang gesetzt wurde? Kann es tatsächlich die Natur gewesen sein, die ein solches Urteil verkündet hat? Wenn die Existenz der Wesen im Kosmos Unruhe hervorruft, begehen alle Wesen den gleichen Fehler: Den der Geburt, so die anaximandrische These. Und wenn ja, ist das in Kraft gesetzte Gesetz der Zeit das totalitäre Gesetz, das diejenigen auswählt, die die Ordnung, die diesem Regime auferlegt wird, stören. Was wäre aus einer solchen Perspektive die adäquateste individuelle Handlung, da alle zum Leben gehören und da niemand dem unerbittlichen Schicksal entkommen kann?

Der Adler und der Rabe sind Symbole für Chaos und Katastrophe und agieren gemeinsam, während die sonstigen Vogelarten wegen des harten Winters sterben. Der Erzähler selbst fühlt sich wie einer dieser Vögel, wenn er einerseits das Chaos und andererseits das unausweichliche Schicksal sieht - die anaximandrische These. Was in diesem Szenario visualisiert wird, ist die pessimistische Atmosphäre, die die Szene wiederum durchdringt und abschließt.

Schließlich erreicht der Konsul sein Ziel, Frau Wetterhuses Haus, und beendet die Bewegung durch die Topographie. Er kehrt in einen geschlossenen Raum zurück. Dieser Raum ist aber privat, und nicht öffentlich wie das Konsulat:

Es herrschte dort winterliche Strenge, ein Geruch nach nicht zu bändigem Schimmel und aufgeweichter Menschlichkeit. Wandteppiche, Türvorhänge, uralte Möbel, all das verschmierte miteinander: Schneeasche. Die Seltsamkeit dieser lichtfeindlichen und antiweltlichen Umgebung, betäubt und halbtot, und das Gefühl von Einsamkeit waren erschreckend; rundum ein kalter Hauch. Sie hatten den Kamin angezündet. Von den Kronleuchtern schien Kerzenlicht herab, Friedhofslicht. Man rechnete damit, von Kobolden und Lemuren umrundet zu sein. Es befanden sich Lebewesen im Raum, fünf Frauen insgesamt, alle betagt, die sich erstarrt, fermatestatisch und verschreckt zurückzogen in ihre Samt- oder Wollkleider mit hohen Krägen und langen Ärmeln; ein schrecklicher Zierrat. ${ }^{55}$

55 Ebda., S. 921-922. Im Original: «Havia lá uma invernia de austeridade, o cheiro de irrenovável mofo e de humanidade macerada. Tapeçarias, reposteiros de falbalás, muitos antigos móveis, tu- 
Das Ambiente nimmt andere Konturen an und die Gerüche, die Helligkeit und die Temperatur nehmen den Fokus in den Kommentaren des Erzählers ein. Der Raum wird als kellerartig beschrieben und die Atmosphäre wird drückender, erstens, weil der Konsul das Gefühl hat, dass er in die Eingeweide der Erde eindringe, zweitens, weil der Raum wie aus einer anderen Zeit wirkt: «Ich klingelte und man führte mich in einen kellerartigen Salon». ${ }^{56}$ Die unterirdische Umgebung scheint wie eine vorübergehende Unterbrechung der Zeit, die das Gefühl vermittelt, das Leben sei abgeschafft worden, die Zeit schreitet voran, aber es gibt eine Beständigkeit in der Gewohnheit, alles ist alt, Menschen und Gegenstände.

Die Idee eines außer Kraft gesetzten Lebens wird sowohl durch die Wörter verstärkt, die mit dem Altmodischen, Alten und dem bereits Toten verknüpft sind («solífugo», «antimundano», «sopor», «semiviver», «solidão») («Die Seltsamkeit dieser lichtfeindlichen und antiweltlichen Umgebung, betäubt und halbtot, und das Gefühl von Einsamkeit waren erschreckend; rundum ein kalter Hauch»), als auch durch die Kommentare des Erzählers zur Leuchtkraft und den Umweltgerüchen. Der von Kerzenlicht beleuchtete Saal ist mit den Lichtern eines Friedhofs verbunden, der Geruch von Schimmel durchdringt den Raum, die Gegenstände sind alt und scheinen zu anderen Zeiten zu gehören; zu einer anderen Realität. Obwohl der Kamin beleuchtet ist, erzeugt er keine Wärme, um die Umgebung zu wärmen, und die kalte Luft umgibt den gesamten Raum, in dem sich die Asche des Schnees befindet.

Der Kommentar des Erzählers zu den anwesenden Personen verdeutlicht den Gedanken einer ungewöhnlichen Umgebung, wenn er diejenigen mit Kobolden und Lemuren ${ }^{57}$ vergleicht, die er später als «Lebewesen» und «Frauen» bezeichnet. Es waren fast bewegungslose und schweigende Lebewesen. Die Hauptfigur wird als eine pupillenlose Statue ohne Iris beschrieben, als außerordentlich alt, das Gesicht von Erschöpfung geprägt, alles eckig, von Furchen ausgehöhlt, in denen tiefe Augen lagen.

Nach den Kommentaren des Erzählers über die Umgebung und über die Figuren bekommt die Szene noch für einen kurzen Moment eine neue und fast feierliche Dynamik, die aus Erinnerungen einer glücklichen Vergangenheit besteht, als

do se unia num esfumado: as cinzas da neve. Assutava a esdruxularia daquele ambiente solífugo e antimundano, de sopor e semiviver, o sentido da solidão; circunstado um ar frio. Tinham acendido a lareira. Dos lustres descia uma luz, de velas, era luz em cemitério. Esperava-se encontrar, em torno, duendes e lêmures. Encontravam-se criaturas - ao todo cinco mulheres, todas velhas, que se retraíam, estafermáticas, estornicadas nas vestes de veludo ou gorgorão de lã, de golas altas, longas mangas, terrível decoro.»

56 Ebda., S. 921.

57 In Rom waren die Lemuren Geister, die mit dem Tod in Verbindung gebracht wurden. 
die alte Dame in Brasilien wohnte und in die Stadt Petropolis zum Kaiser ging. Die Dame bekommt ihre Stimme zurück und fängt an, mit dem Konsul auf Portugiesisch zu sprechen. Die Vergangenheit betrifft dann den düsteren gegenwärtigen Moment und die vergangene Sonne wird von der Realität des totalitären Staats verdunkelt. Der erzählerische Ton bekommt einen beschleunigten Rhythmus und wird von kurzen und bestätigenden Sätzen gegliedert. Sie zeigen die Dringlichkeit der Lage und die Verzweiflung Verônikas, die ihre Tochter retten möchte. Die Erinnerung verknüpft Vergangenheit und Gegenwart.

Es ist der verzweifelte Versuch und die letzte Option, die anaximandrische These zu erreichen. Die negative Antwort des Konsuls auf Verônicas Bitte unterbricht die rhythmische Bewegung der Szene. Es herrscht wieder Stille und die alte Dame, deren Name in der Schreibweise im Laufe des Textes variiert, kehrt in ihren Zustand der Lähmung zurück. Die Unmöglichkeit, sich die Zukunft vorzustellen, dominiert jeden und die anaximandrische Atmosphäre weicht dem in Bewegung gesetzten anaximadrischen Gesetz der Zeit, in dem es in der Gegenwart kein Leben mehr gibt:

[...] Ich erhob mich; ich war nicht einmal ein passiver Helfer des Schicksals. Auch die anwesenden Frauen erhoben sich in ernster, vornehmer Höflichkeit. In ihnen brodelten die Gedanken. Müde Seelen. Nur Stille. Dona Verônica ließ ihr langes Gesicht sehen, das wie abgenutztes, verblasstes, durchscheinendes Pergament wirkte. [...] Alle standen wir zu ihren Füßen um sie herum. Die lange Frau. Die Weltordnung. Das alte Leben. ${ }^{58}$

Die Erzählung besteht aus einer kreisenden Struktur und nimmt Themen wieder auf (ring composition), die in unterschiedlichen Situationen erscheinen. Diese kompositionelle Form wird in der Erzählung thematisch, graphisch und lexikalisch verdeutlicht. Auch der Titel «A velha» («Die Greisin») spiegelt sich im letzten Satz der Erzählung «A velha vida» («Das alte Leben») wider. Eine ähnliche Struktur - vor allem auf der Ebene des Akustischen - lässt sich auch in der Zwischenszene «Todos pertencíamos, assim, mesmo, à vida» («Jeder von uns ist, trotz allem, Teil des Lebens») nach dem Zitat der anaximandrischen These finden, als auch in dem Satz, «Todos nós jazíamos, em pé, em volta dela» («Alle standen wir zu ihren Füßen um sie herum»), der dem Ende der Erzählung vorangeht. Die zweite Spiegelung kann als eine Fortsetzung der ersten interpretiert werden, was darauf hinweist, dass der Tod das Endziel ist, obwohl alle zum Leben gehören.

58 Ebda., S. 923. Im Original: «Levantei-me; eu nem era um cooperador passivo do destino. Também aquelas senhoras presentes se levantaram, em sincera, distinta cortesia. Ali, borbulhavam pensamentos. Desfalecidos espíritos. Só silêncio. Dona Verônica mostrava-nos seu comprido rosto, escalavrado, blafardo, diáfano pergaminho. Dona Angélica passava-lhe meiga a mão por trás da cabeça. Todos nós jazíamos de pé, em volta dela. A longa mulher. $\mathrm{O}$ sistema do mundo. A velha vida.» 


\section{Fazit}

Abschließend kann festgestellt werden, dass durch die anaximandrische These direkte Verbindungen zwischen der Wirkung der Bedeutung und der Wirkung der Produktion der Präsenz hergestellt werden. Wobei letztere dafür verantwortlich ist, die dem Narrativ zugrunde liegenden Sinneffekte zu potenzieren und neu zu dimensionieren. Die Subjektivität der Biografie ergibt sich aus der Begegnung, der Resonanz und den implizierten Einflüssen im gemeinsamen Feld zwischen der ästhetischen Kreation und der gelebten Erfahrung, die parallel zu den Beschreibungen von Temperaturen und Umgebungen, in denen sich der Erzähler bewegt, auftreten und die seinen Geisteszustand widerspiegeln.

Auch wenn die Erzählung selbst eine eigene Einheit darstellt, verstärkt das Wissen um die Biografie des Autors und um die historischen Ereignisse den Sinnund Präsenzeffekt in der Geschichte. Nicht nur die Emotionen des Textes berühren den Verstand des Lesenden, sondern auch die ästhetische Erfahrung auf einer anderen Ebene, die Erfahrung des Lebens in einem bestimmten historischen Moment, der von einer bedrückenden Atmosphäre bestimmt wird.

Die Erfahrung des Kontextes beeinflusst direkt die Wahrnehmung des Präsenzeffekts, der autobiografischen Isotopie und der Gemeinschaft, die nicht nur durch die individuellen Kompetenzen des Individuums konstruiert wird. Denn die Erinnerung wird auch in Bezug auf die kollektive Erinnerung, die die kollektive Psychologie ausmacht, entwickelt. So sind die Erinnerungen nicht nur individuell, sondern auch gemeinsam, in Abhängigkeit mit der sozialen Umgebung konstruiert. Der Schriftsteller verwendet, um seinen Diskurs herzustellen, verschiedene Diskurse, weil er sich nicht nur daran erinnert, was er selbst erlebt hat, sondern auch die Erinnerungen seiner Gemeinschaft in sich trägt.

Der Erzähler der Geschichte «A velha» lässt sich von der anaximandrischen These leiten und nutzt sie als Rechtfertigung für das, was er nicht kontrollieren kann. Er drückt den Pessimismus aus, der aus seinen Beschränkungen resultiert. Beschränkungen, die nicht durch seinen Charakter, sondern durch die Atmosphäre und die historische und politische Realität um ihn herum bedingt sind. Er wandelt jedoch seine Erfahrung in Sprache um. Das Bild, das in der Geschichte kreiert wird, betont die Einschränkung individueller Handlungen, sei es, um in die Geschichte einzugreifen oder sie zu verändern. Die Figuren müssen sich dem Schicksal und dem kosmischen Gesetz unterwerfen. Beim Deuten der Erzählung ist es wesentlich zu unterscheiden, ob Rosa an die Unmöglichkeit menschlichen Handelns angesichts ungerechter Realität glaubt, oder ob der Glaube an die anaximandrische These als individuelle Rechtfertigung für unterlassenes Handeln und Zögern angesichts von Ungerechtigkeit kritisiert wird. Dies zu entscheiden, bleibt jedem/r Lesenden und der Erzählung selbst überlassen. 
